\title{
Gecombineerde leefstijlinterventies voor mensen met een lage SES?
}

\author{
Lisanne Mulderij · Kirsten Verkooijen · Annemarie Wagemakers
}

Published online: 18 February 2019

(C) The Author(s) 2019

Sinds januari 2019 worden de zorggerelateerde onderdelen van een Gecombineerde Leefstijlinterventie (GLI), zoals de leefstijlcoach of de diëtist, vergoed vanuit de basisverzekering. Voorwaarde is dat mensen een gewichtsgerelateerd gezondheidsrisico hebben, dat ze zijn doorverwezen door een huisarts, dat het om een door het RIVM erkende GLI gaat en dat de zorggroep een contract heeft met de zorgverzekeraar (zie het Spectrum-artikel van Aldien Poll, verderop in dit nummer). De huidige erkende GLI's (CooL, Slimmer en BeweegKuur) zijn echter niet specifiek ontwikkeld voor mensen met een lage sociaaleconomische status (SES). Doordat zorg-en beweegaanbieders vanwege de vergoeding alleen erkende GLI's aanbieden, krijgen andere GLI's weinig of geen kans zich (verder) te ontwikkelen. De vraag is hoe we tot een systeem komen waarin dit wel mogelijk blijft.

\section{Sociaaleconomische gezondheidsverschillen}

Overgewicht en obesitas komen vaker voor bij mensen met een lagere opleiding dan bij hoger opgeleiden. Bijna de helft van de volwassen Nederlanders heeft overgewicht en bijna $14 \%$ is obees [1]. Voor mensen met een lage opleiding is dit percentage respectievelijk $66 \%$ en $23 \%$. Hoewel al jaren getracht wordt deze percentages naar beneden te krijgen is de verwachting dat deze cijfers de komende jaren zullen stijgen [2]. Ook het terugdringen van sociaaleconomische gezondheidsverschillen staat hoog op de politieke agenda, maar ook dit is nog niet gelukt.

L. Mulderij $(\bowtie)$

Gezondheid en Maatschappij, Wageningen University \& Research, Wageningen, Nederland

lisanne.mulderij@wur.nl

\section{Gecombineerde leefstijlinterventies (GLI's)}

Een positieve ontwikkeling is dat huisartsen sinds januari 2019 de mogelijkheid hebben om mensen met een verhoogd gewichtsgerelateerd gezondheidsrisico een GLI aan te bieden, waarbij de zorggerelateerde begeleiding binnen een GLI wordt vergoed vanuit de basisverzekering. Allereerst omdat een deel van de behoefte aan deze zorg kan worden voorkomen door preventie en gezondheidsbevordering, hoewel curatieve zorg altijd nodig blijft. Ten tweede omdat GLI's gezondheid bevorderen door een compleet begeleidingspakket aan te bieden, gericht op meerdere leefstijlfactoren, bijvoorbeeld voeding én bewegen. Door ook een leefstijlcoach aan het aanbod toe te voegen kan persoonlijke begeleiding geboden worden, bijvoorbeeld op het gebied van roken of alcoholgebruik, en kan de intrinsieke motivatie voor een gezonde leefstijl worden verhoogd [3].

\section{GLI's voor mensen met een lage SES}

De drie GLI's die in 2019 vanuit de basisverzekering vergoed worden zijn echter niet specifiek ontwikkeld voor mensen met een lage SES. Het is daarom de vraag of deze GLI's ook voor hen effectief zijn. Zij hebben niet alleen vaker te maken met overgewicht, maar ervaren ook vaker (een combinatie van) andere aandoeningen en problemen, bijvoorbeeld chronische stress, armoede, schulden, werkloosheid en/of psychische problemen. Bij mensen met een lage SES is het verbeteren van de eigen gezondheid vaak niet de eerste prioriteit. Een GLI ontwikkeld en uitgevoerd met en voor mensen met lage SES kan hierop inspelen.

Ervaring met een GLI specifiek voor mensen met een lage SES in Arnhem laat zien dat langere, intensieve begeleiding door een leefstijlcoach gewenst is [4]. Deelnemers aan deze GLI ervaren de leefstijl- 
coach als een 'stok achter de deur' om hun nieuwe, gezonde leefstijl vast te houden. Een leefstijlcoach van de gemeente heeft korte lijnen met andere afdelingen en organisaties binnen een gemeente en kan mensen ondersteunen bij het vinden van de juiste begeleiding, om zo meerdere problemen aan te pakken. Vanwege de vaak aanwezige armoede en schulden is het aan te raden de financiële drempels voor het verbeteren van de gezondheid bij deze groep mensen zo laag mogelijk te houden. In Arnhem is daarom afgesproken dat het beweegdeel van de GLI voor mensen met een lage SES de eerste drie maanden door de gemeente wordt vergoed. Daarna kunnen de deelnemers tegen een gereduceerd tarief sporten (met de Gelrepas).

\section{Van erkende GLI's naar criteria?}

Vanwege de voorwaarden voor de vergoeding vanuit de basisverzekeringen moeten zorg- en beweegaanbieders kiezen voor erkende GLI's, die niet specifiek zijn ontwikkeld voor mensen met een lage SES. Dit is jammer, omdat specifieke doelgroepen zo waarschijnlijk niet het aanbod krijgen dat het best bij hen past. Ook heeft dit consequenties voor wetenschappelijk onderzoek naar GLI's, bijvoorbeeld voor inzicht in hoe GLI's impact kunnen hebben op mensen met een lage SES. Om aan te tonen wat werkt en waarom, is namelijk verder onderzoek naar de werkzame elementen van deze GLI's nodig [4]. Hoewel het RIVM aangeeft dat het nog steeds mogelijk is om nieuwe interventies aan te melden voor het erkenningstraject, is het lastig om zorg- en beweegaanbieders te vinden die bereid zijn om in het kader van onderzoek een (nog) niet erkende GLI uit te voeren. Het gevolg is onvoldoende deelnemers die meedoen aan niet-erkende GLI's, en daardoor onvoldoende 'power' voor het aantonen van effectiviteit.

Een mogelijk alternatief voor het aanbieden van GLI's is het opstellen van criteria - op basis van onderzoek naar werkzame elementen van GLI's - waaraan een GLI minimaal moet voldoen om vergoed te wor- den vanuit de basisverzekering. Hierbij kan gedacht worden aan een minimaal aantal uur leefstijlbegeleiding door een leefstijlcoach, een minimaal aantal uur diëtetiek, de vereiste minimale scholing van de aanbieders, enzovoort. Op die manier krijgen ook kleinere, opkomende en mogelijk meer specifieke GLI's een kans zich te bewijzen, kunnen huisartsen makkelijker verwijzen naar het voor hen bekende lokale aanbod, en kan worden aangesloten bij meer specifieke doelgroepen in hun specifieke context. We beseffen dat ook een lijst met criteria niet voor elke doelgroep hetzelfde kan zijn en de ontwikkeling van innovatieve interventies in de weg kan staan. Het blijven verstrekken van subsidies voor innovatie van GLI's is daarom de enige manier om te zorgen voor een blijvend passend en gevarieerd aanbod van GLI's.

Open Access This article is distributed under the terms of the Creative Commons Attribution 4.0 International License (http://creativecommons.org/licenses/by/4.0/), which permits unrestricted use, distribution, and reproduction in any medium, provided you give appropriate credit to the original author(s) and the source, provide a link to the Creative Commons license, and indicate if changes were made.

\section{Literatuur}

1. RIVM. Overgewicht. 2018. https://www.volksgezond heidenzorg.info/onderwerp/overgewicht. Geraadpleegd op: 16 nov 2018.

2. RIVM. Leefstijl. 2018. https://www.vtv2018.nl/leefstijl. Geraadpleegd op: 16 nov2018.

3. Rutten GM, Meis JJ, Hendriks MR, et al. The contribution of lifestyle coaching of overweight patients in primary care to more autonomous motivation for physical activity and healthy dietary behaviour: Results of a longitudinal study. Int JBehav Nutr Phys Act. 2014;11(1):86.

4. Wagemakers A, Mulderij LS, Verkooijen KT, et al. Care-physical activity initiatives in the neighbourhood: Study protocol for mixed-methods research on participation, effective elements, impact, and funding methods. BMCPublic Health. 2018;18(1):812. 